\title{
RESEARCH PAPER \\ Analogy of physicochemical attributes of two grape seeds cultivars
}

\author{
Seyed Mohammad Ahmadi ${ }^{1}$, and Barat Ali Siahsar ${ }^{2}$ \\ 'Department of Food Science and Technology, Faculty of Agriculture, University of Zabol, P.O. box 98615- \\ 538, Postal code 98613-35856, Zabol, Iran. \\ ${ }^{2}$ Department of Plant Breeding and Biotechnology, Faculty of Agriculture, University of Zabol, P.O. box \\ 98615-538, Postal code 98613-35856, Zabol, Iran.
}

\begin{abstract}
S. M. Ahmadi, and B. A. Siahsar. 2011. Analogy of physicochemical attributes of two grape seeds cultivars. Cien. Inv. Agr. 38(2): 291-301. In this study, a range of physicochemical properties (dimensions, kernel volume, mass unit, bulk and true densities, porosity, terminal velocity, static friction coefficient against different surfaces, oil content and fatty acids composition) of the Bojnordi and Fakhri cultivars of grape seeds were studied. Fatty acid composition for both cultivars of grape seeds consisted of palmitic, stearic, oleic, linoleic and linolenic acid. The values for palmitic, stearic, oleic, linoleic and linolenic acid for the Bojnordi cultivar were 9.56, 4.37, 22.87, 62.85 and $0.33 \%$ and for the Fakhri cultivar were 9.22, 4.33, $19.75,66.40$ and $0.28 \%$, respectively. All physical properties of the grape seed cultivars were significantly affacted by the moisture content in the studied range (11.5 to 23.9 w.b.\%). For both cultivars (Bojnordi and Fakhri), the relationships between physical properties and moisture content were linear.
\end{abstract}

Key words: Chemical properties, fatty acid, grape seed, physical properties.

\section{Introduction}

Grape (Vitis vinifera L.), one of the largest fruit crops worldwide, are mainly used for juice and wine production. Grape pomace is the solid waste product leftover from wine and juice processing, and generally consists of pulp, skins, and seeds. It is mainly used as animal feed, due to its high fiber content (Palma et al., 2001), or in the production of alcohol. Grape seeds, however, have been traditionally sold to the oil extraction industry, and there has been a recent increase in their demand in the cosmetic and pharmaceutical sectors, given their utility as a

Received February 22, 2010. Accepted June 3, 2011. Corresponding author: info@siahsar.com source of antioxidants. Depending on the conditions of the grape at harvest time and the type of press used, $13.5-14.5 \%$ of the overall volume of grapes crushed becomes grape pomace waste, with extremes of waste production as high as 20\% (Russ and Meyer-Pittroff, 2004). This high-volume waste product contains several valuable components, such as tannins, phytochemicals, and oil.

The use of pomace within the food industry represents an opportunity to lower production costs and create new food sources for human consumption. Grape seeds, which comprise 20 to $26 \%$ of the pomace (Kamel et al., 1985), have a high protein content (Ohnishi et al., 1990). They also have an oil content of 10 to $20 \%$ (Schuster, 1992) and are rich in vitamin E, which has important health benefits. Grape seed oil consists 
mainly of triglycerides (TG), which are comparatively rich in unsaturated fatty acids, such as oleic and linoleic acids, in relation to other oil-rich seeds (Barron et al., 1988). The polyunsaturated fatty acids, such as linoleic and linolenic acids, are essential for human metabolism. Given the lack of enzymes responsible for synthesis of these fatty acids, they must be taken from daily foods. It has been reported that grape seed oil is rich in linoleic acid (Barron et al., 1988; Schuster, 1992). As such, its oil can be used as a source of edible vegetable oil (Ohnishi et al., 1990). Grape seed oil is high-quality culinary oil, possessing a high smoke point $\left(252^{\circ} \mathrm{C}\right)$, which makes it a good choice for frying and other high-temperature food applications. Due to its stability and fluidity properties, grape seed oil spreads and mixes better with food, than other oils, such as sunflower, soybean, cotton and colza oil (Arvanitoyannis et al., 2006).

In the last three decades, significant progress has been made in the development of measurement techniques and the accumulation of data concerning the physical properties of biological and agro food materials. The major moisturedependent physical properties of biological materials are shape and size, bulk density, true density, porosity, mass unit, friction against various surfaces, terminal velocity and angle of repose (Mohsenin, 1980). These properties have been studied for various agricultural materials such as rapeseed (Çalışır et al., 2005), caper (Dursun and Dursun, 2005), pomegranate (Kingsly et al., 2006), safflower (Baümler et al., 2006), sunflower (Gupta and Das, 1997), cotton (Ozarslan, 2002), cumin (Singh and Goswami, 1996), canola (White and Jayas, 2001), pigeon pea (Baryeh and Mangope, 2002), lentil (Scanlon et al., 2005), green soybean (Sirisomboon et al., 2007), pistachio nut (Kashaninejad et al., 2006), rice (Corrêa et al., 2007), peanut (Aydin, 2007), and sorghum (Mwithiga and Sifuna, 2006).

The size, shape and physical dimensions of grape seed are important in sizing, sorting, sieving and other separation processes. The densities of grape seed are necessary for the design of processing and storage equipment. Porosity affects the resistance to airflow through bulk grape seed. Terminal velocity is critical for the design of pneumatic conveyors, which transport grape seed using air and separate grape seed from undesirable materials. During the handling, processing and storage of grape seed, the product exerts frictional forces on machinery components or storage structures. The magnitude of these frictional forces determines the amount of power required to convey the material. Static friction between the grape seed and a conveyor belt affects the maximum angle at which the conveyor transport grape seed. (Mohsenin, 1980; White and Jayas, 2001). Therefore, the determination and consideration of these properties plays an important role in the grape seed industry.

The objective of this study was to compare some physicochemical properties of two cultivars of grape seeds, Bojnordi and Fakhri, as a function of moisture content in the range of 11 to $23 \%$ (w.b.).

\section{Materials and methods}

\section{Measured properties}

In this research, two cultivars of grape seeds at five moisture content levels were investigated with respect to their dimensions, geometric mean diameter, sphericity, unit mass, kernel volume, true density, bulk density, porosity, and static coefficient of friction against various surfaces and terminal velocity. The oil content and fatty acid composition of seeds were also determined.

\section{Sample preparation}

Seventy kilograms of two cultivars of grape (Bojnodi and Fakhri) was purchased form a local market in Mashhad (province of Khorasan, Iran), and their seeds were separated from the pomace and sun-dried. The seeds were manually cleaned to remove all foreign materials, and broken seeds were eliminated. The initial moisture content of samples was determined by drying about $15 \mathrm{~g}$ of samples in an air convec- 
tion oven at $103 \pm 2{ }^{\circ} \mathrm{C}$ until a constant weight was obtained (ASAE S352.2). The process was repeated three times to determine mean values.

In order to obtain samples with higher moisture content, a calculated quantity of distilled water was added to the sample. The quantity of distilled water was calculated from the following equation:

$$
W_{2}=W_{1} \times\left[\frac{M_{1}-M_{2}}{100-M_{1}}\right]
$$

where $W_{1}, W_{2}, M_{1}$, and $M_{2}$ are sample weight (g), distilled water weight $(\mathrm{g})$, final moisture content (w.b.\%) and initial moisture content (w.b.\%), respectively. Then, the sample was sealed and kept at $4^{\circ} \mathrm{C}$ in a refrigerator for at least a week to enable the moisture to distribute uniformly throughout the product. It was necessary to let the samples to warm up to room temperature before starting each test (Kashaninejad et al., 2006). All the physical properties of both seed cultivars were measured at five moisture contents in the range of $11-23 \%$ (w.b.).

\section{Determination of oil content and fatty acid composition}

Soxhlet extraction was employed to determine the total oil content of $20 \mathrm{~g}$ of milled grape seeds. Fatty acids of the grape seed oil were analyzed using gas chromatography (GC) (Agilent Chemstation, 6890N) with a flame ionization detector (FID) and a Permabond FFAP stainless steel column $(120 \mathrm{~m} \times 0.25 \mathrm{~mm}$, BPX70, Australia, SGE). Esterification of the fatty acids was performed acording to Marquard (1987). Briefly, 20 dried grape seeds were homogenized with $400 \mathrm{~mL}$ iso-octane/iso-propanol (9:1, v:v), and the upper phase was removed and put into $2 \mathrm{~mL}$ sodium methylate (5 g sodium methylate, $800 \mathrm{~mL}$ methanol, $200 \mathrm{~mL}$ iso-octane). After orbital shaking followed by a 30-minute wait, $0.7 \mathrm{~mL}$ of iso-octane was added to the mixture. Then, $0.5 \mu \mathrm{L}$ of upper phase containing fatty acid methylesters (FAME) was injected into the column of GC. The operation conditions of GC were as follows: detector temperature, $240{ }^{\circ} \mathrm{C}$; injector temperature, $250{ }^{\circ} \mathrm{C}$; column temperature, $120{ }^{\circ} \mathrm{C}(3$ minute hold $)$ to $200{ }^{\circ} \mathrm{C}$ at $3{ }^{\circ} \mathrm{C} /$ minute (6 minute hold); split ratio, $50: 1 \mathrm{~mL} / \mathrm{H}$; and helium was used as a carrier gas.

\section{Dimensions, sphericity and mass unit}

In order to determine dimensions, sphericity, and unit mass, one hundred grape seeds at each moisture level were randomly selected, and three principal dimensions, namely, minor diameter (thickness), intermediate diameter (width) and major diameter (length), were measured for each using an electronic digital caliper (GUANGLU), which was accurate to $0.01 \mathrm{~mm}$. To obtain the unit mass, each seed was weighed on a precision electronic balance (Sartorius, TE313S) with a reading to $0.001 \mathrm{~g}$. Geometric mean diameter and degree of sphericity were calculated at each moisture level using following equations (Mohsenin, 1980):

$$
D=(L W T)^{1 / 3} \quad \phi=\frac{(L W T)^{1 / 3}}{L} \times 100
$$

where $D, \phi, L W T, L, W$, and $T$ are geometric mean diameter (mm), sphericity (\%), seed volume, seed length $(\mathrm{mm})$, seed width $(\mathrm{mm})$ and seed thickness $(\mathrm{mm})$, respectively.

\section{Volume, bulk density, true density and porosity}

Bulk density was calculated from the mass and volume of the circular container with known volume $(0.5 \mathrm{~L})$ that was filled with the grape seeds. After filling the circular container, excess seeds were removed by passing a stick across the top surface using five zigzag motions. The samples were not compacted in any way.

The true density, defined as the ratio of the mass of the seed to the true volume occupied by the sample, was determined using an electronic balance reading to $0.001 \mathrm{~g}$ and a pycnometer (Baümler et al., 2006). Grape seed volume was determined using the liquid displacement method. Toluene (C7H8) was used instead of water because it is less readily absorbed by seeds 
and because its low surface tension allows it to feel even shallow seed depressions (Mohsenin, 1980 ). The porosity $(\varepsilon)$ of the bulk is the ratio of spaces in the bulk to its bulk volume and was determined by the following equation (Mohsenin, 1980):

$$
\varepsilon=\frac{\rho_{t}-\rho_{b}}{\rho_{t}} \times 100
$$

where $\varepsilon, \mu, \rho$ and $\rho_{t}$ are porosity (\%), coefficient of static friction, bulk density $\left(\mathrm{kg} \mathrm{m}^{-3}\right)$ and true density $\left(\mathrm{kg} \mathrm{m}^{-3}\right)$, respectively.

\section{Coefficient of static friction}

Coefficient of static friction for grape seeds was determined against surfaces of galvanized iron, plywood, concrete, fiberglass and rubber at different moisture contents. A wooden box of 100 $\mathrm{mm}$ length, $100 \mathrm{~mm}$ width and $40 \mathrm{~mm}$ height without a base or lid was filled with the sample and placed on an adjustable tilting plate faced with the test surface. The sample container was raised slightly $(5-10 \mathrm{~mm})$ so that it did not touch the surface. The inclination of the test surface was increased gradually with a screw device until the box started to slide downward, and then, the angle of tilt $(\alpha)$ was read from a graduated scale. For each iteration, the sample in the container was emptied and refilled with a new sample (Joshi et al., 1993; Olajide et al., 2000; Kashaninejad et al., 2006). The coefficient of static friction was calculated from the following relationship:

$$
\mu=\operatorname{tg} \alpha
$$

where $\mu$ is coefficient of static friction and $\operatorname{tg} \alpha$ is tangant of repose angle.

\section{Terminal velocity}

The terminal velocity of grape seeds at different moisture content were measured using an air column. For each test, a sample was dropped from the top of a 100-mm-diameter, 2-m-long glass tube. The air flowed upwards in the tube, from bottom to the top, and the air velocity at which the sample suspended was recorded by a hot wire anemometer with at least $0.01 \mathrm{~m} \mathrm{~s}^{-1}$ sensitivity. Ten iterations were performed for each moisture content level (Joshi, et al., 1993; Aydin and Ozcan, 2002; Gezer et al., 2002; Kashaninejad et al., 2006).

\section{Data analysis}

Unless otherwise noted, all these experiments were replicated three times, and the average values are reported. The effects of moisture content on different physical properties of grape seed were determined using analysis of variance (ANOVA), and significant differences of means were compared using Duncan's test at the $1 \%$ significance level. The optimal relationship between moisture content and physical properties of grape seeds was determined using regression analysis. Analysis of data was performed using SAS 9.2 software.

\section{Results and discussion}

\section{Oil content and fatty acid composition}

The oil contents and some oil quality properties of grape seeds obtained from the two cultivars are given in Table 1. The values for oil content obtained are 16 and $14.7 \%$ for the Bojnordi and Fakhri cultivars, respectively. These results were

Table 1. Oil contents and selected oil quality properties of the two cultivars of grape seeds.

\begin{tabular}{lccccccc}
\hline & \multirow{6}{*}{$\begin{array}{c}\text { Oil } \\
\text { content } \\
\text { Cultivar }\end{array}$} & Fatty acid composition (\%) & Legree of \\
\cline { 3 - 7 } & $(\%)$ & Palmitic & Stearic & Oleic & Linoleic & Linolenic & $\begin{array}{c}\text { Degaturation } \\
\text { uns) }\end{array}$ \\
\hline Bojnordi & 16.0 & 9.56 & 4.37 & 22.87 & 62.85 & 0.33 & 86.07 \\
Fakhri & 14.7 & 9.22 & 4.33 & 19.75 & 66.40 & 0.28 & 86.45 \\
\hline
\end{tabular}


similar to those obtained by Ohnishi et al. (1990), Schuster (1992) and Baydar and Akkurt (2001). They reported that the seeds of the different grape cultivars contained 9.9 to $20.0 \%$ oil. Fatty acid composition of grape seeds consisted of palmitic, stearic, oleic, linoleic, and linolenic acids for both cultivars. The values for palmitic, stearic, oleic, linoleic, and linolenic acids in the Bojnordi cultivar were 9.56, 4.37, 22.87, 62.85 and $0.33 \%$ and for the Fakhri cultivar were 9.22, 4.33, 19.75, 66.40 and $0.28 \%$, respectively. Other researchers have also reported that grape seed oil contains mainly palmitic, stearic, oleic, and linoleic acids (Baydar and Akkurt, 2001; Barron et al., 1988; Schuster, 1992). Baydar and Akkurt (2001) reported that the ranges of fatty acids in the seeds of 18 grape cultivars were 6.5 to $9.7 \%$ for palmitic acid, 3.5 to $7.3 \%$ for stearic acid, 17.8 to $26.5 \%$ for oleic acid, 60.1 to $70.1 \%$ for linoleic acid and less than $1 \%$ for linolenic acid. The fatty acid composition of grape seed oil is similar to that of safflower, sunflower, soybean, maize and cotton seed oils, which are of the linoleic type (Weiss, 1983). The fatty acid composition of grape seed oil is similar to that of sunflower oil. Sunflower oil generally comprises $60 \%$ linoleic, $25 \%$ oleic, $8 \%$ palmitic and $5 \%$ stearic acid (Weiss, 1983).

The degree of unsaturation in the grape seed oil (Table 1) was over $86 \%$ due to unsaturated fatty acid. High levels of unsaturation play an important role in lowering high blood cholestrol and also in the treatment of atherosclerosis (Axtell, 1981). Poly-unsaturated fatty acids, such as linoleic and linolenic acids, are essential for the human body because they cannot be synthesized in the body. As such, grape seed oil, which is very rich in linoleic acid, may be a valuable source of dieatery fat. Grape seed oil was rather poor in linolenic acid. Low levels of linolenic acid are desirable in edible oils because high levels of this fatty acid can result in undesirable odors and tastes. Furthermore, because linolenic acid is easily oxidized due to its having three double bonds on its hydrocarbon chain, the stability or shelf-life of an oil rich in linolenic acid would be too short. Because of its low quantities of linolenic acid, grape seed oil also has advantages in terms of human health and shelf-life.

\section{Dimensions and unit mass}

Table 2 shows the dimensions and mass of two grape seeds cultivars at various moisture contents in the range of 11.5 to 23.9 (w.b.\%). Significant differences were observed among the measured parameters with increases in moisture content. Increases of moisture content caused an increase in grape seed size. The dimensions of both seed cultivars increased linearly with increasing moisture content. Similar results were found by Deshpande et al. (1993) for soybeans, Gezer et al. (2002) for apricot pits and kernels and Carman (1996) for lentil seeds. The relationship between length, width, thickness and unit mass and moisture content of grape seeds for the Bojnordi and Fakhri cultivars are given by the following equations:

$$
\begin{aligned}
& L_{\mathrm{b}}=2.4107 M_{C}+7.3696\left(\mathrm{R}^{2}=0.94\right) \\
& L_{\mathrm{f}}=0.6167 M_{C}+7.6744\left(\mathrm{R}^{2}=0.95\right) \\
& W_{\mathrm{b}}=1.3187 M_{C}+4.3538\left(\mathrm{R}^{2}=0.98\right)
\end{aligned}
$$

Table 2. Dimensions and unit mass of the two cultivars of grape seeds.

\begin{tabular}{lccccc}
\hline Cultivar & $\begin{array}{c}\text { Moisture } \\
\text { content (w.b.\%) }\end{array}$ & $\begin{array}{c}\text { Length } \\
(\mathrm{mm})\end{array}$ & $\begin{array}{c}\text { Width } \\
(\mathrm{mm})\end{array}$ & $\begin{array}{c}\text { Thickness } \\
(\mathrm{mm})\end{array}$ & $\begin{array}{c}\text { Mass } \\
(\mathrm{g})\end{array}$ \\
\hline Fakhri & 11.5 & $7.74 \pm 0.43$ & $4.39 \pm 0.30$ & $2.95 \pm 0.26$ & $0.047 \pm 0.005$ \\
& 16.8 & $7.78 \pm 0.40$ & $4.46 \pm 0.25$ & $2.97 \pm 0.30$ & $0.052 \pm 0.052$ \\
& 19.8 & $7.80 \pm 0.38$ & $4.51 \pm 0.32$ & $3.05 \pm 0.24$ & $0.054 \pm 0.006$ \\
& 23.8 & $7.81 \pm 0.43$ & $4.55 \pm 0.31$ & $3.09 \pm 0.25$ & $0.055 \pm 0.006$ \\
& & & & & \\
Bojnordi & 11.6 & $7.62 \pm 0.58$ & $4.49 \pm 0.19$ & $2.92 \pm 0.25$ & $0.048 \pm 0.005$ \\
& 15.9 & $7.78 \pm 0.56$ & $4.58 \pm 0.30$ & $2.97 \pm 0.26$ & $0.053 \pm 0.006$ \\
& 19.7 & $7.84 \pm 0.38$ & $4.61 \pm 0.26$ & $3.03 \pm 0.26$ & $0.054 \pm 0.006$ \\
& 23.9 & $7.91 \pm 0.46$ & $4.67 \pm 0.26$ & $3.08 \pm 0.31$ & $0.058 \pm 0.008$ \\
\hline
\end{tabular}


$W_{\mathrm{f}}=1.2881 M_{C}+4.2555\left(\mathrm{R}^{2}=0.98\right)$

$T_{\mathrm{b}}=1.360 M_{\mathcal{C}}+2.756\left(\mathrm{R}^{2}=0.99\right)$

$T=0.046 M_{C}+2.894\left(\mathrm{R}^{2}=0.95\right)$

$M_{\mathrm{b}}=0.072 M_{C}+0.0405\left(\mathrm{R}^{2}=0.95\right)$

$M_{\mathrm{f}}=0.0652 M_{C}+0.0407\left(\mathrm{R}^{2}=0.92\right)$

Geometric mean diameter and sphericity

Table 3 shows the sphericity and geometric mean diameter of grape seeds at different moisture contents. The sphericity and geometric mean diameters of both cultivars increased with increasing moisture content. When the moisture content increased, the sphericity of the grape seeds increased from 31.10 to $32.32 \%$ and from 32.11 to $32.20 \%$ for the Bojnordi and Fakhri cultivars, respectively. Calculated values of the geometric mean diameter varied from 2.479 to 2.492 and from 2.477 to $2.487 \mathrm{~mm}$ for the Bojnordi and Fakhri cultivars, respectively. The relationship between sphericity and moisture content and the relationship between geometric mean diameter and moisture content were found to have the following values for the Bojnordi and Fakhri cultivars, respectively:

$\phi_{\mathrm{b}}=8.8195 M_{C}+30.122\left(\mathrm{R}^{2}=0.96\right)$

$\phi_{\mathrm{f}}=0.7831 M_{C}+32.014\left(\mathrm{R}^{2}=0.95\right)$

Table 3. Sphericity and geometric mean diameter of the two grape seeds cultivars. w.b.:wet basis.

\begin{tabular}{lccc}
\hline Cultivar & $\begin{array}{c}\text { Moisture } \\
\text { Content } \\
\text { (w.b.\%) }\end{array}$ & $\begin{array}{c}\text { Sphericity } \\
(\%)\end{array}$ & $\begin{array}{c}\text { Geometric } \\
\text { mean } \\
\text { diameter }(\mathrm{mm})\end{array}$ \\
\hline Fakhri & 11.5 & $32.11 \pm 1.55$ & $2.477 \pm 0.030$ \\
& 16.8 & $32.13 \pm 1.35$ & $2.480 \pm 0.030$ \\
& 19.8 & $32.16 \pm 1.53$ & $2.485 \pm 0.024$ \\
& 23.8 & $32.20 \pm 1.83$ & $2.487 \pm 0.035$ \\
& & & \\
Bojnodi & 11.6 & $31.10 \pm 2.23$ & $2.479 \pm 0.045$ \\
& 15.9 & $31.56 \pm 1.68$ & $2.481 \pm 0.034$ \\
& 19.7 & $31.75 \pm 1.26$ & $2.483 \pm 0.029$ \\
& 23.9 & $32.32 \pm 1.92$ & $2.492 \pm 0.039$ \\
\hline
\end{tabular}

$$
\begin{aligned}
& D_{\mathrm{b}}=0.0955 M_{C}+2.4671 \quad\left(\mathrm{R}^{2}=0.89\right) \\
& \mathrm{D}_{\mathrm{f}}=0.0866 M_{C}+2.4672\left(\mathrm{R}^{2}=0.98\right)
\end{aligned}
$$

\section{Bulk density}

The experimental results of the bulk density for grape seeds at different moisture levels are presented in Figure 1. As the moisture content increased from 11.5 to $23.9 \%$, the bulk density of the Fakhri and Bojnordi cultivars decreased from 603 to 590 and from 587 to $570 \mathrm{~kg} \mathrm{~m}^{-3}$, respectively. The decrease in the bulk density of both grape seed cultivars following an increase in moisture content indicates that the increase in mass owing to moisture gain in the sample is less than the accompanying volumetric expansion of the bulk. The negative linear relationship between bulk density and moisture content was observed by Deshpande et al. (1993) with respect to soybean, by Carman (1996) with respect to lentil, by Gupta and Das (1997) with respect to sunflower and by Konak et al. (2002) with respect to chick pea. The following equations were obtained to show the relationship between moisture content and bulk density of the Bojnordi and Fakhri cultivars, respectively:

$$
\begin{aligned}
& \rho_{b f}=-1.3882 M_{c}+600.88\left(\mathrm{R}^{2}=0.90\right) \\
& \rho_{b b}=-1.0789 M_{c}+615.14\left(\mathrm{R}^{2}=0.99\right)
\end{aligned}
$$

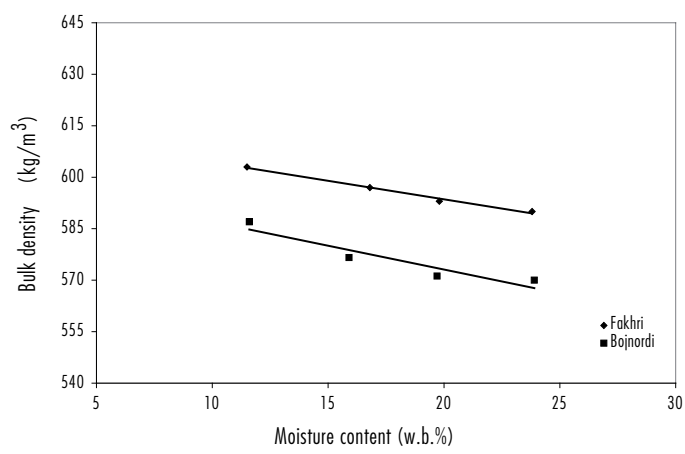

Figure 1. Effect of moisture content on the bulk density of the grape seeds cultivars. w.b.:wet basis. 
Kernel volume

Figure 2 presents kernel volume changes of grape seeds at different moisture contents. When the moisture content increased from 11.5 to $23.9 \%$ (w.b.\%), the kernel volume of both cultivars of grape seeds were observed to increase linearly from 0.047 to 0.053 and from 0.048 to $0.052 \mathrm{~cm}^{3}$ for the Bojnordi and Fakhri cultivars, respectively. The moisture content had no signifficant effect on the kernel volume of either grape seed cultivar. The following equations were shown to represent the relationship between moisture content and kernel volume of the Bojnordi and Fakhri cultivars:

$$
\begin{aligned}
& V_{b}=0.0005 M_{c}+0.0418\left(\mathrm{R}^{2}=0.96\right) \\
& V_{f}=0.0003 M_{c}+0.0446\left(\mathrm{R}^{2}=0.89\right)
\end{aligned}
$$

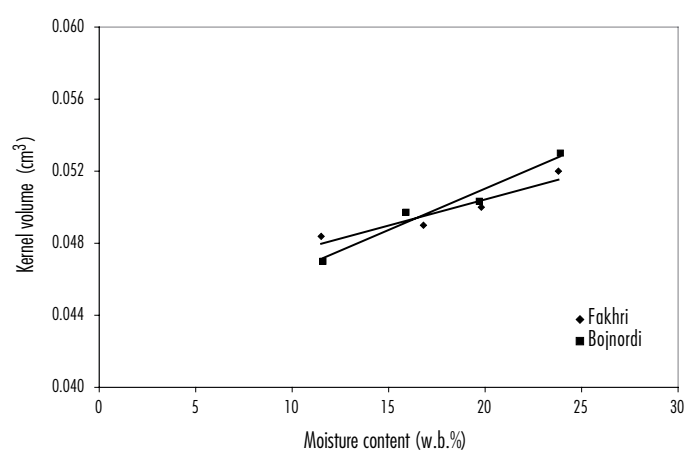

Figure 2. Effect of moisture content on the kernel volume of the two grape seed cultivars. w.b.:wet basis.

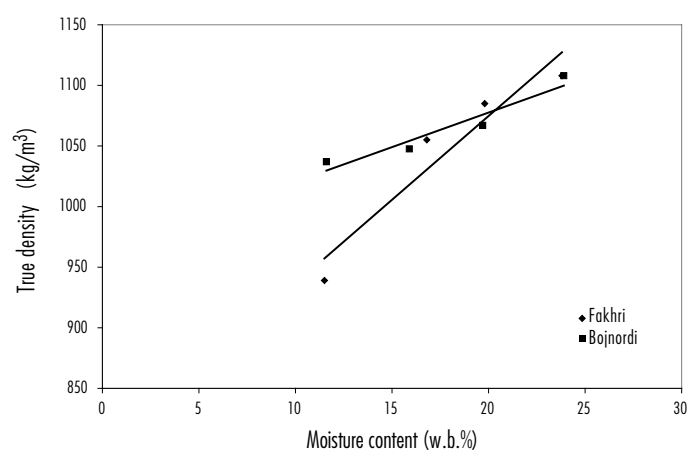

Figure 3. Effect of moisture content on the true density of the two grape seeds cultivars. w.b.:wet basis.
True density

The variation in true density with respect to moisture content for both cultivars of grape seeds is shown in Figure 3. The true density of grape seeds at different moisture levels varied from 1037 to 1108 and from 939 to 1108 $\mathrm{kg} \mathrm{m}^{-3}$ for the Bojnordi and Fakhri cultivars, respectively. The increasing trend of the true density of grape seeds may be attributed to the higher moisture gain of the seeds compared to their volumetric expansion. An increase in true density in response to an increase in moisture content has been reported for cumin (Singh and Goswami, 1996), sunflower (Gupta and Das, 1997), pigeon pea (Baryeh and Mangope, 2002), and pistachio nut (Kashaninejad et al., 2006); however, Deshpande et al. (1993) and Ozarslan and Konak et al. (2002) found the true densities of soybean, cotton and chickpea to decrease as the moisture content increased. The relationship between moisture content and true density appears to be linear for both cultivars, which can be represented by the following equations:

$$
\begin{aligned}
& \rho_{\mathrm{b}}=5.7049 M_{c}+963.5\left(\mathrm{R}^{2}=0.92\right) \\
& \rho_{t f}=13.834 M_{c}+798.08\left(\mathrm{R}^{2}=0.91\right)
\end{aligned}
$$

\section{Porosity}

Because porosity depends on the bulk as well as true densities, the magnitude of variation in porosity depends only on these factors. The values of porosity were calculated using the data on bulk and true densities of the grape seeds, and the results are presented in Figure 4. Porosity increased from 43.4 to $48.5 \%$ and from 35.8 to $46.8 \%$ for the Bojnordi and Fakhri cultivars, respectively. A similar trend was reported with for sunflower (Gupta and Das, 1997), lentil (Scanlon et al., 2005) and pigeon pea (Baryeh and Mangope, 2002), but a different trend was reported for pistachio nut (Kashaninejad et al., 2006) and soybean (Sirisomboon et al., 2007). The relationship between moisture content and porosity appears to be linear for both cultivars, which can be represented by the following equations: 
$\varepsilon_{b}=0.4175 M_{c}+38.424\left(\mathrm{R}^{2}=0.99\right)$

$\varepsilon_{f}=0.8983 M_{c}+26.675\left(\mathrm{R}^{2}=0.91\right)$

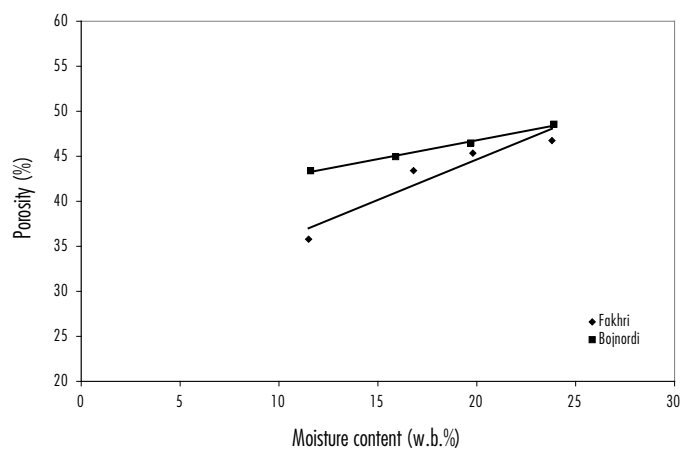

Figure 4. Effect of moisture content on the porosity of the two grape seeds cultivars. w.b.:wet basis.

\section{Static coefficient of friction}

Table 4 shows the static coefficient of friction for the Bojnordi and Fakhri cultivars as determined with respect to galvanized iron, plywood, fiberglass, concrete and rubber surfaces at different moisture contents. At all of the moisture contents, the static coefficient of friction was highest for both cultivars with respect to rubber. It was observed that the static coefficient of friction for grape seeds on all surfaces increased linearly with increasing moisture content. The relationships between these coefficients against various surfaces and moisture contents of grape seeds cultivars are shown in Table 5. The reason for the increased friction coefficient at higher moisture content may be because the water present in the seeds acts as a cohesive force on the contact surface. As the moisture content of seeds increases, the surface of the samples becomes stickier. Water tends to adhere to surfaces, and the water on the moist seed surface would be attracted to the surface across which the sample is being moved. Other researchers have also found that, as the moisture content increased, the static coefficient of friction increased (Kashaninejad et al., 2006; Joshi et al., 1993; Gezer et al., 2002; Carman, 1996; Gupta and Das, 1997).

\section{Terminal velocity}

The variation in terminal velocity of grape seed cultivars (Bojnordi and Fakhri) with respect to moisture content of the sample is presented in Figure 5. The terminal velocity was found to increase from 7.51 to 8.28 and from 7.40 to $8.83 \mathrm{~m} \mathrm{~s}^{-1}$ for the Bojnordi and Fakhri cultivars, respectively, in the moisture range of 11.5 to $23.9 \%$ (w.b.\%). As the moisture content increased, the terminal velocity was found to increase linearly. The increase in terminal velocity following an increase in moisture content can be attributed to the increase in mass of an individual sample per unit frontal area facing the air stream. The other reason for this increase is that the drag force is affected by the moisture content of particle. Joshi et al. (1993), Carman

Table 4. Static coefficient of friction of the two grape seeds cultivars at different moisture contents.

\begin{tabular}{lcccccc}
\hline Cultivar & $\begin{array}{c}\text { Moisture } \\
\text { Content (w.b.\%) }\end{array}$ & Galvanized iron & Plywood & Fiberglass & Concrete & Rubber \\
\hline Fakhri & 11.5 & 0.40 & 0.39 & 0.38 & 0.48 & 0.48 \\
& 16.8 & 0.52 & 0.53 & 0.54 & 0.55 & 0.59 \\
& 19.8 & 0.53 & 0.56 & 0.59 & 0.57 & 0.62 \\
& 23.8 & 0.57 & 0.57 & 0.62 & 0.59 & 0.65 \\
& 11.6 & & & & & \\
Bojnordi & 15.9 & 0.32 & 0.44 & 0.33 & 0.49 & 0.52 \\
& 19.7 & 0.49 & 0.50 & 0.50 & 0.56 & 0.58 \\
& 23.9 & 0.52 & 0.51 & 0.53 & 0.57 & 0.60 \\
\hline w.b.:wet basis. & & 0.59 & 0.56 & 0.59 & 0.61 & 0.62 \\
\hline
\end{tabular}


Table 5. Relationships between the static coefficient of friction against different surfaces and the moisture content of the two grape seed cultivars.

\begin{tabular}{|c|c|c|c|c|}
\hline Cultivar & $\begin{array}{c}\text { Moisture } \\
\text { content (w.b.\%) }\end{array}$ & Surface & Equation & $\mathrm{R}^{2}$ \\
\hline \multirow[t]{5}{*}{ Fakhri } & $11.5-23.8$ & Concrete & $\mu=0.0086 \mathrm{Mc}+0.3915$ & 0.92 \\
\hline & & Galvanized iron & $\mu=0.0135 \mathrm{Mc}+0.2611$ & 0.92 \\
\hline & & Fiber glass & $\mu=0.0183 \mathrm{Mc}+0.1963$ & 0.89 \\
\hline & & Plywood & $\mu=0.0151 \mathrm{Mc}+0.2414$ & 0.87 \\
\hline & & Rubber & $\mu=0.0139 \mathrm{Mc}+0.3333$ & 0.95 \\
\hline \multirow[t]{5}{*}{ Bojnordi } & $11.6-23.9$ & Concrete & $\mu=0.0085 \mathrm{Mc}+0.4048$ & 0.85 \\
\hline & & Galvanized iron & $\mu=0.0204 \mathrm{Mc}+0.1135$ & 0.90 \\
\hline & & Fiber glass & $\mu=0.0196 \mathrm{Mc}+0.1386$ & 0.88 \\
\hline & & Plywood & $\mu=0.0092 \mathrm{Mc}+0.3403$ & 0.92 \\
\hline & & Rubber & $\mu=0.0081 \mathrm{Mc}+0.4353$ & 0.89 \\
\hline
\end{tabular}

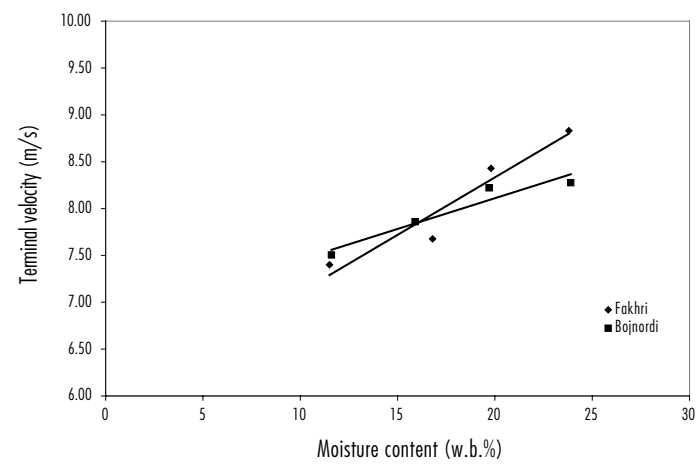

Figure 5. Effect of the moisture content on the terminal velocity of the two grape seeds cultivars. w.b.:wet basis.

(1996), Gupta and Das (1997), Gezer et al. (2002) and Kashaninejad et al. (2006) found similar results for pumpkin, lentil, sunflower, apricot pit and kernel and pistachio nut, respectively. The relationship between moisture content and terminal velocity can be represented by the following equations:

$V_{t b}=0.0656 M_{c}+6.7992\left(\mathrm{R}^{2}=0.93\right)$

$V_{t f}=0.1227 M_{c}+5.8791\left(\mathrm{R}^{2}=0.93\right)$

This study revealed that the seeds of two cultivars of grape (Fakhri and Bojnordi) contain 14.7 to $16.0 \%$ oil. Baydar and Akkurt (2001) showed that the oil concentration of 18 grape cultivar seeds ranged from 11.6 to $19.6 \%$. The presence of fatty acids, such as linoleic and linoleic acids in grape seed oil, both of which have important heath benefits, can be considered to be valuable in edible oils. Baydar and Akkurt (2001) showed that oleic and linoleic acids of grape seeds range from 17.8 to $26.5 \%$ and from 60.1 to $70.1 \%$, respectively. Several engineering properties of the two cultivars of grape seeds were also investigated with respect to moisture content in the range of 11.5 to 23.9 (w.b.\%). The results indicated that the modifications of moisture content of grape seed caused a linear variation on several different physical properties. Razavi and Fathi (2009) showed that the average values of seed length, width, thickness, geometric mean diameter, surface area, filling angle of repose, and terminal velocity decreased linearly with a decrease in the moisture content. This study also found that there is a difference in the physiochemical properties of the Bojnordi and Fakhri cultivars of grape seeds. In addition, all physical properties of the two cultivars depend on their moisture contents. In particular, these properties are very useful in the design of equipment involved in processing, transportation, and storage. Given that Khorasan is the main grape-producing region in Iran (15.42\%) and that Bojnordi and Fakhri are the most-cultivated grape cultivars in Khorasan (FAO 2005), taking advantage of the difference in the seed properties of these cultivars will assist in the design of more versatile machinery for the processing of grapes in Khorasan. 


\title{
Resumen
}

\begin{abstract}
S. M. Ahmadi y B. A. Siahsar. 2011. Analogía de los atributos físico-químicos de dos cultivares de semillas de uva. Cien. Inv. Agr. 38(2):291-301. En este estudio fueron estudiadas una serie de propiedades físico-químicas (dimensiones, el volumen del núcleo, unidad de masa, volumen y densidad real, porosidad, la velocidad terminal, coeficiente de fricción estática con materiales diferentes, contenido de aceite y composición de ácidos grasos) en los cultivares de semillas de uva Bojnordi y Fakhri. Composición de ácidos grasos de los dos cultivares de semillas de uva consistió de ácido palmítico, esteárico, oleico, linoleico y linolénico. Los valores de ácido palmítico, esteárico, oleico, linoleico y linolénico, para el cultivar Bojnordi fueron 9.56, 4.37, 22.87, 62.85 y 0.33\% y para el cultivar Fakhri fueron 9.22, 4.33, 19.75, 66.40 y $0.28 \%$, respectivamente. Todas las propiedades físicas de los cultivares de semilla de uva se afectado significativamente por el contenido de humedad en el rango estudiado (11,5 a 23,9 w.b.\%). Para los dos cultivares (Bojnordi y Fakhri), las relaciones entre las propiedades físicas y contenido de humedad fueron lineales.
\end{abstract}

Palabras clave: Ácidos grasos, propiedades físicas, propiedades químicas, semilla de uva.

\section{References}

Arvanitoyannis, I.S., D. Ladas, and A. Mavromatis. 2006. Potential uses and applications of treated wine waste: a review. Int. J. Food Sci. Technol. 41: 475-487.

Axtell, J.D. 1981. Breeding for Improved Nutritional Quality. In: Frey K.J. (ed.). Plant Breeding II. The Iowa State Univ. Press. Iowa. 497 pp.

Aydin, C., and M. Ozcan. 2002. Some physico-mechanic properties of terebinth fruits. J. Food Engin. 53: 97-101.

Aydin, C. 2007. Some engineering properties of peanut and kernel. J. Food Engin. 79: 810-816.

Barron, L.J.R., M.V. Celaa, G. Santa-Maria, and N. Corzo. 1988. Determination of the triglyceride composition of grapes by HPLC. Chromatographia 25: 609-612.

Baryeh, E.A., and B.K. Mangope. 2002. Some physical properties of QP-38 variety pigeon pea. J. Food Engin. 56: 59-65.

Baümler, E., A. Cuniberti, S.M. Nolasco, and I.C. Riccobene. 2006. Moisture dependent physical and compression properties of safflower seed. J. Food Engin. 72: 134-140.

Baydar, N.G., and M. Akkurt .2001. Oil content and oil quality properties of some grapes seeds. Turk J. Agric. 25: 163-168.

Çalışır, S., T. Marakoğlu, H. Öğüt, and Ö. Öztürk. 2005. Physical properties of rapeseed (Brassica napus oleifera L.). J. Food Engin. 69: 61-66.
Carman, K. 1996. Some physical properties of lentil seeds. J. Agric. Engin. Res. 63: 87-92.

Corrêa, P.C., S.F. Da Silva, C. Jaren, P.C. Afonso Júnior, and I. Arana. 2007. Physical and mechanical properties in rice processing. J. Food Engin. 79: 137-142.

Deshpande, S.D., S. Bal, and T.P. Ojha. 1993. Physical properties of soybean. J. Agric. Engin. Res. 56: 89-98.

Dursun, E., and I. Dursun. 2005. Some physical properties of caper seed. Biosyst. Engin. 92: 237-245.

FAO. Food and Agriculture Organization. 2005. Available online at: http://www.fao.org (Website accessed May 7, 2010).

Gezer, I., H. Haciseferogullari, and F. Demir. 2002. Some physical properties of hacihaliloglu apricot pit and kernel. J. Food Engin. 56: 49-57.

Gupta, R.K., and S.K. Das. 1997. Physical properties of sunflower seeds. J. Agric. Engin. Res. 66: 1-8.

Joshi, D.C., S.D. Das, and R.K. Mukherjee. 1993. Physical properties of pumpkin seeds. J. Agric. Engin. Res. 54: 219-229.

Kamel, B.B., H. Dawson, and Y. Kakuda. 1985. Characteristics and composition of melon and grape seed oils and cakes. JAOCS 62: 881-883.

Kashaninejad, M., A. Mortazavi, A. Safekordi, and L.G. Tabil. 2006. Some physical properties of Pistachio (Pistacia vera L.) nut and its kernel. J. Food Engin. 72: 30-38.

Kingsly, A.R.P., D.B. Singh, M.R. Manikantan, and R.K. Jain. 2006. Moisture dependent physical 
properties of dried pomegranate seeds (Anardana). J. Food Engin. 75: 492-496.

Konak, M., K. Carman, and C. Aydin. 2002. Physical properties of chickpea seeds. Biosyst. Engin. 82: 73-78.

Marquard, R. 1987. Qualitatsanalytik im dienste der ölpflanzenzüchtung. Fat. Sci. Technol. 89: 95-99.

Mohseni, M., T. Ohe, M.R. Fazeli, S.N. Ostad, M. Hamedi, H. Jamalifar, and E. Azizi. 2006. Studying the mutagenicity of red florets safflower IL111 using Ames Test. Journal of Pharmacology and Toxicol. 1: 545-551.

Mohsenin, N.N. 1980. Physical properties of plants and animal materials. Gordon and Breach Science Publishers. New York, USA. 891 pp.

Mwithiga, G., and M.M. Sifuna. 2006. Effect of moisture content on the physical properties of three varieties of sorghum seeds. J. Food Engin. 75: 480-486.

Ohnishi, M., S. Hirose, M. Kawaguchi, S. Ito, and Y. Fujino. 1990. Chemical composition of lipids, especially triacylglycerol, in grape seeds. Agric. Biol. Chem. 54:1035-1042.

Olajide, J.O., B.I.O. Ade-Omowaye, and E.T. Otunola. 2000. Some physical properties of shea kernel. J. Agric. Engin. Res. 76: 419-421.

Ozarslan, C. 2002. Physical properties of cotton seed. Biosyst. Eng. 83: 169-174.

Palma, M., Z. Piñeiro, and C.G. Barroso. 2001. Sta- bility of phenolic compounds during extraction with superheated solvents. J. Chromatogr. 921: 169-174.

Razavi, S.M.A. and M. Fathi. 2009. Moisture-dependent physical properties of grape (Vitis vinifera L.) seed. Philipp. Agric. Scientist 92: 201-212.

Russ, W., and R. Meyer-Pittroff. 2004. Utilizing waste products from the food production and processing industries, Crit. Rev. Food Sci. 44: 57-62.

Scanlon, M.G., S. Cenkowski, K.I. Segall, and S.D. Arntfield. 2005. The physical properties of micronised lentil as a function of tempering moisture. Biosyst. Engin. 92: 247-254.

Schuster, W.H. 1992. Ölpflanzen in Europa. DLGVerlag. Frankfurt am Main. 240 pp.

Singh, K.K., and T.K. Goswami. 1996. Physical properties of cumin seed. J. Agric. Eng. Res. 64: 93-98.

Sirisomboon, P., P. Pornchaloempong, and T. Romphophak. 2007. Physical properties of green soybean: criteria for sorting. J. Food Engin. 79: $18-22$.

Weiss, E.A. 1983. Oilseed Crops. Tropical Agriculture Series. Longman, London, England. 660 pp.

White, N.D.G., and D.S. Jayas. 2001. Physical properties of canola and sunflower meal pellets. Can. Biosys. Engin. 43: 49-52. 
